\title{
Electronic Pathfinders in Academic Libraries: An Analysis of Their Content and Form
}

\section{Candice Dahl}

Forty-five electronic pathfinders were selected from nine Canadian university libraries to assess their degree of conformity to suggested guidelines in the existing literature about pathfinders. The content and the format of the chosen pathfinders were assessed in terms of consistency and scope. Also considered were overall readability and whether they were effectively constructed to be used as starting points for further research. The analysis revealed that the guidelines were not uniformly followed, leaving some pathfinders more complex and less useful than others. Further, it demonstrated that specific guidelines must be created for electronic pathfinders because they pose particular problems that are not addressed in the current literature about pathfinders in general.

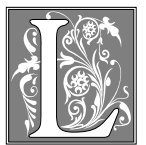

ibrary pathfinders, or subject guides, are used in many academic libraries to help library users with their initial research needs by making them aware of various resources and how they can be used. ${ }^{1}$ As more and more sources of information are made available, librarians strive to facilitate the use of such resources by library users through pathfinders. Although pathfinders have existed traditionally in the form of paper handouts, they are becoming increasingly popular in electronic form as additions to most library Web pages and include advice about finding information online. Well-constructed pathfinders can be beneficial in many situations, such as when the librarian on duty is unfamiliar with the literature of certain subjects. Further, those pathfinders available online can be used by people who are not even in the library.
To maximize their usefulness, however, librarians must be aware of several issues when creating and making pathfinders available. The format of each library's pathfinders should be consistent, and the scope of each should be manageable. Further, pathfinders must be readable to users and should start equipping them to go beyond the resources listed and conduct their own research. Such guidelines are useful to keep in mind because, as the following analysis of fortyfive electronic pathfinders reveals, failure to do so leaves some pathfinders more complex and less useful than others. Moreover, because they are intended to be reliable and appropriate guides for student researchers, it is important that pathfinders be constructed carefully. The purpose of this study is to assess current guidelines for the creation of pathfinders by applying them to electronic pathfind-

Candice Dahl is a Master's Student, Faculty of Information Studies, at the University of Toronto: e-mail: cddahl@sprint.ca. 
ers that have been posted on the Web sites of nine university libraries. By analyzing existing pathfinders, this study will assess how well these general ideas are incorporated into the making of pathfinders. A further goal is to raise awareness of the problems commonly posed by electronic pathfinders. It is hoped that looking at the general guidelines already suggested, and uncovering strengths and weaknesses of existing electronic pathfinders, will encourage librarians to build on what others have done in order to create pathfinders that are both easy-to-use and beneficial research tools.

\section{Literature Review}

The number of pathfinders available to students certainly exceeds the amount of literature that has been published on how to create them. Before the availability of extensive online resources and the advent of online pathfinders, Charles H. Stevens, M. P. Canfield, and J. J. Gardner pointed out that pathfinders should not be merely comprehensive subject bibliographies but, rather, constructed to serve as "a kind of map to the resources of the library." ${ }^{2}$ They were to be instructional tools and could be useful in reference service, particularly when a subject specialist was unavailable. Alice Sizer-Warner, emphasizing the helpfulness of pathfinders and advocating their use as teaching tools, stressed that they should be uniform and brief. ${ }^{3}$ Patricia Breivik suggested that all library handouts be "compatible in style and format" and that pathfinders, which "outline basic search procedures," should be "incorporated appropriately into library instruction program activities." After testing the readability of library guides, Lorna Peterson and Jamie W. Coniglio emphasized the need to eliminate jargon and ensure that library users are able to understand the pathfinders that are produced. ${ }^{5}$ More recently, Harry Nuttall and Sonja McAbee advised the inclusion of pathfinders in online catalogs because they can be "starting points for library research" that also "extend the depth of the catalog." ${ }^{\prime 6}$ Corinne Laverty, in her exploration of electronic Web guides and library instruction, stressed that pathfinders must be "well designed, well advertised and readily accessible."

Although all of these authors advocate the use of pathfinders, and some even offer very general guidelines about creating them, only Jim M. Kapoun has offered a "format and construction guide to aid librarians in preparing readable, useful pathfinders." ${ }^{8} \mathrm{He}$ suggested that pathfinders should serve as introductory maps to the resources at hand and not be exhaustive bibliographies. Their format should be consistent and simple, and they "should not dictate a single 'correct way' to perform topical research." ${ }^{9}$ Finally, pathfinders should be broad in scope, covering topics that are likely to be studied and will remain so over time. Although Kapoun's guidelines incorporate the comments of other authors, they do not take into account the specific challenges posed by online pathfinders. These challenges must be recognized in order to ensure the usability of the pathfinders. It was expected that the analysis of electronic pathfinders would reveal the guidelines suggested by Kapoun and others to be useful, although not comprehensive with regard to electronic pathfinders because they raise unique issues regarding usability and consistency. Thus, there is a need to update the guidelines so as to benefit the large number of university libraries that present their pathfinders electronically.

This study assesses only electronic pathfinders and does not serve as a comparison between them and print versions. Further, because the intention was not to analyze pathfinders that listed only electronic resources, libraries whose pathfinders focused on them exclusively were excluded from the study. Moreover, it should be kept in mind that this analysis is not an evaluation of the appropriateness or completeness of the resources listed for each subject area. Finally, evaluating pathfinders themselves does not reveal how often they are used nor how students actually use them. This is a sepa- 
rate question, but one that deserves further study, especially in light of the amount of time and effort that librarians put into creating and updating pathfinders.

\section{Methodology}

Forty-five electronic pathfinders were chosen to assess their degree of conformity to guidelines suggested in the literature about pathfinders and formulated most explicitly by Kapoun. Issues arising from the analysis and not addressed by Kapoun also will be highlighted. Although Kapoun's categories have not been adopted exactly as he presented them, his ideas, in combination with those of other writers, are the basis of those categories that have been formulated. The content and the format of the chosen pathfinders were assessed in terms of their consistency and scope. Also considered were their overall readability and whether they were effectively constructed for use as starting points for further research.

In July and August of 2000, electronic pathfinders were chosen from the library Web sites of top-ranking Canadian universities according to the annual ranking conducted by Maclean's in 1999. The universities were divided into three categories by Maclean's: medical/doctoral, comprehensive, and primarily undergraduate. Medical/doctoral universities are those that have a medical school and offer a range of Ph.D. programs. Comprehensive universities have a range of undergraduate and graduate programs, as well as a significant amount of research activity. Universities in the primarily undergraduate category are those that focus on undergraduate, rather than graduate, programs. Five humanities-oriented electronic pathfinders, from libraries that produced pathfinders referring to both electronic and print resources, were selected from the three top-ranking universities in each of the three categories. Some university library systems produced pathfinders containing only electronic resources; as a result, these libraries were excluded and the next highest-ranking university library system was chosen. For example, Mount Allison (ranked first in the primarily undergraduate category) did not have electronic pathfinders referring to more than electronic resources, and so the schools ranking second, third, and fourth were included. In the medical/doctoral category, the University of Toronto (ranked first) did not have electronic pathfinders, and so McGill (ranked fourth) was included. Wherever possible, pathfinders for the same (or closely related) subject were chosen from each library. The analysis below is based on the pathfinders shown in figure 1.

\section{Consistency is easier to maintain in pathfinders that are simple and direct in structure, rather than excessively hierarchical or sprawling.}

Forty-five pathfinders were examined and rated in each of the four categories described below. Those for each library were rated as a set in the consistency category, but individually in the other three categories. The pathfinders were ranked on a scale of 1 to 3 , with 1 being the lowest possible score. A score of 1 was given to pathfinders in categories where they rated poor overall. A score of 2 was assigned when the pathfinders had some positive and some negative qualities. In categories where the positive qualities far outweighed the negative qualities, a score of 3 was assigned. In the case where the actual pathfinders could not be found, even though they were listed on the library's Web site, no numerical value was assigned. After initially coding the pathfinders according to this scale, accuracy of the coding was verified by having two independent coders rate a random sample of twelve pathfinders. Using Ole R. Holsti's composite reliability coefficient, intercoder reliability was determined to be 93.2 percent. $^{10}$ This result suggests high reliability for the findings of the study. After the scores of the pathfinders for each university were totaled, the average score for each category of univer- 
FIGURE 1

Electronic Pathfinders Divided among Three Types of Universities

\section{Medical/Doctoral:}

British Columbia: Classics, English Literature, History, Philosophy, Religious Studies (http://www.library.ubc.ca/home/subjects/)

Queen's: Classics, English Literature, History, Philosophy, Religion (http://library.queensu.ca/libguides/subject.htm)

McGill: Classics, English Literature, History, Philosophy, Religious Studies (http://www.library.mcgill.ca/subjectguides.htm)

\section{Comprehensive:}

Guelph: Art History, Canadian Literature, English Literature, Philosophy, Religion (http://www.lib.uoguelph.ca/pathfinders/index.html)

Simon Fraser: English Literature, History, Philosophy, Poetry Criticism, Visual Arts (http://www.lib.sfu.ca/kiosk/research.htm\#subject)

Waterloo: Classics, English, History, Philosophy, Religion (http://www.lib.uwaterloo.ca/discipline/discip.html)

\section{Primarily Undergraduate:}

Acadia: Church History, Classics, English Literature, History, Systematic Theology (http://www.acadiau.ca/vaughan/guides/)

St. Francis Xavier: Art, English Literature, History, Music, Philosophy

(http://libmain.stfx.ca/newlib/services/reference/welcome.htm)

Trent: Classical Studies, English Literature, History, Modern Languages, Philosophy (http://www.trentu.ca/library/guides/libres.shtml)

sity was found by adding the totals and dividing the result by three. In the final analysis, specific examples will be highlighted to demonstrate the reasons for placing each pathfinder in the chosen category.

It should be noted at the outset that in the online environment, it is very easy to refer library users from a central, discipline-specific Web page to other Web pages for information of interest, such as a general introduction on how to use the library catalog or a list of appropriate Internet links. This method of providing information fractures pathfinders; it forces students who want to explore and learn to use the full range of listed resources to look at several pages, albeit from a central location. In many cases, this reality has made it difficult to identify the "real" pathfinder, if one truly even exists apart from the rest of the links. Whenever possible, the objects of analysis for this study have been the main bodies of works listed that include print resources specific to the library that posted the pathfinder. Sometimes this list includes information on the library catalog and online resources, for example, and sometimes it does not. Thus, when it is stated in the analysis that a pathfinder does not contain such information, the implication is not that the information does not exist on the site. Rather, attention is merely being drawn to the fact that the information is not contained compactly within the con- 
fines of a single, perusable, and printable resource, which is what pathfinders traditionally have been understood to be.

The pathfinders were analyzed according to the following four categories:

- consistency;

- scope;

- readability;

- use/usability.

Consistency of format and information refers to the degree to which the pathfinders from each library resemble each other in terms of type of information provided and form of presentation. Such consistency facilitates ease of use if more than one pathfinder is consulted and visually unifies the publications of the library. Consistency is easier to maintain in pathfinders that are simple and direct in structure, rather than excessively hierarchical or sprawling. The groups of pathfinders that were rated low in this category exhibited a great degree of variation from pathfinder to pathfinder in terms of information presented and/or format. Those rated high were consistent in both content and form.

The second category considered was that of scope. First, each pathfinder should cover a subject that is not so narrow so as to be of little use, but not so broad that the subject cannot really be covered at all. The scope should be defined on the pathfinders so that users know what is being covered and whether their topic is included. Also, pathfinders should point to a full range of resources, such as the library catalog, journal article indexes, Internet sites, and reference sources. Pathfinders that were either hopelessly broad in subject area or narrow in terms of types of resources listed, for example, were placed in the low category. Those that had manageable boundaries and included references to a range of core resources were rated higher.

Readability is an important category because it is difficult for students to use something they cannot navigate or understand. Ensuring readability requires the inclusion of descriptive annotations, but the exclusion (or explanation) of jargon.
Moreover, readability relates to the ease with which students can find the types of information they seek within the pathfinder. For example, the headings used should accurately define and describe what appears beneath them. With regard to electronic pathfinders, this category also refers to the state of the hypertext links present because, if they cannot be "read" (i.e., are dead or inaccurate), their value is limited. Very complex pathfinders or ones with little explanatory material were ranked lower than those that were direct in presenting the necessary information and kept up to date.

The fourth category deals with how electronic pathfinders were to be used. Pathfinders that are mere bibliographies do not help students learn how to do research. Rather, they provide a list of books to consult and do not teach students how to find other books on their own. Those that list different types of resources, however, and help students to use them (by listing appropriate Library of Congress [LOC] subject headings or general call number areas for browsing, for example) serve as a better starting point for research. Pathfinders exemplifying this second approach rated higher than those with less information on research and explanations about using the different types of resources.

\section{Results}

The data gathered have been organized into three tables, and the results are explained in detail below. The scores of pathfinders in the medical/doctoral category were fairly good (table 1 ) but, as a group, the universities in the comprehensive category clearly ranked the highest (table 2). Although their pathfinders were less consistent than others, they were generally more readable and useful as research tools. The undergraduate libraries received the lowest ratings, and the numbers raise the possibility that it is easier to maintain consistency among less complete pathfinders (table 3 ). The low scores for libraries primarily in undergraduate institutions that might be expected to 
TABLE 1

Ratings of Pathfinders of Universities in the Medical/Doctoral Category (where 3 is the highest score possible)

\begin{tabular}{|c|c|c|c|c|c|}
\hline University & Consistency & Scope & Readability & Use & Total \\
\hline \multicolumn{6}{|l|}{ McGill } \\
\hline Classics & 3 & 2 & 1 & 1 & \\
\hline English & & 2 & 1 & 1 & \\
\hline History & & 2 & 1 & 1 & \\
\hline Philosophy & & 2 & 1 & 1 & \\
\hline \multirow[t]{2}{*}{ Religious studies } & & 2 & 1 & 1 & \\
\hline & & & & & 23 \\
\hline \multicolumn{6}{|l|}{ UBC } \\
\hline Classics & 1 & 1 & 1 & 1 & \\
\hline English & & 2 & 2 & 1 & \\
\hline History & & 1 & 1 & 1 & \\
\hline Philosophy & & 2 & 1 & 2 & \\
\hline \multirow[t]{2}{*}{ Religious studies } & & 2 & 1 & 2 & \\
\hline & & & & & 22 \\
\hline \multicolumn{6}{|l|}{ Queen's } \\
\hline Classics & 2 & 1 & 2 & 1 & \\
\hline English & & 1 & 2 & 1 & \\
\hline History & & 2 & 3 & 2 & \\
\hline Philosophy & & 1 & 2 & 2 & \\
\hline \multirow[t]{2}{*}{ Religion } & & 1 & 2 & 2 & \\
\hline & & & & & 27 \\
\hline Average Score for Mec & Doctoral Categ & & & & 24 \\
\hline
\end{tabular}

have the best or most complete research aids because of the nature of their student body should be noted with concern.

\section{Consistency}

The first point of analysis is consistency of content and format. Acadia's pathfinders are similar in format and simple to navigate. Users can choose from several categories (such as "Reference Shelf," "Books and More," and "Article Indexes") that adequately describe the resources found within. The Reference Shelf is the most comprehensive and subjectspecific part of the pathfinder and includes both electronic and print sources in all five. However, Acadia's systematic theology and church history pathfinders are not arranged as the others are; resources are simply listed rather than arranged in any meaningful way. The format of Guelph's pathfinders is very user-friendly and consistent, other than the remarkable exception of the art history pathfinder. Although it lists the same types of resources as the others, it is not at all similar in presentation. It contains colored backgrounds, pictures, a different structure, and lacks the definition of and statement on the purpose of the pathfinder that others have on the opening page. Simon Fraser has produced relatively uniform pathfinders that are easy to use because of the detailed table of contents at the top of each one. Only the history pathfinder is different in that there is no general list of print resources at Simon Fraser. The others have such a list, and it is annotated in each one. Three of the five pathfinders chosen from St. Francis Xavier are structured in exactly the same way; however, the links to the art and music pathfinders are inactive and lead nowhere. The simplicity and brevity of those posted makes them very straightforward to use and understand, 
and also prevents the user from being overwhelmed by myriad choices. The opening page of each of Waterloo's pathfinders lists a different set of options, so what can be found in one is not necessarily what can be found in another. The English literature pathfinder lists only electronic resources, and the one for history provides links to other online pathfinders (not produced by Waterloo) that cover specific historical topics, so the pathfinders are not specific to Waterloo's collection. The three pathfinders that do include detailed lists of a wide variety of resources (classics, philosophy, and religion) are neither uniform nor straightforward to use because the headings are not always appropriate and change from one pathfinder to another. McGill's pathfinders are completely consistent in format, and each contains a "Brief Guide" in PDF format that lists a variety of resources and call numbers. The University of British Columbia's pathfinders vary in terms of categories covered and type of information included. Also, the history pathfinder

The best pathfinders in terms of readability are Simon Fraser's, which include descriptive and evaluative annotations for the listed resources.

is completely different from the rest and lists mainly electronic resources. Finally, Queen's University's pathfinders are quite consistent in terms of topics covered but differ moderately in format.

\section{Scope}

Defining the scope of a pathfinder and keeping it manageable helps users to know whether it is appropriate for their needs and allows the pathfinder to be rea-

TABLE 2

Ratings of Pathfinders of Universities in the Comprehensive Category (where 3 is the highest score possible)

\begin{tabular}{|c|c|c|c|c|c|}
\hline University & Consistency & Scope & Readability & Use & Total \\
\hline \multicolumn{6}{|l|}{ Waterloo } \\
\hline Classics & 1 & 2 & 1 & 1 & \\
\hline English & & 2 & 1 & 1 & \\
\hline History & & 1 & 1 & 1 & \\
\hline Philosophy & & 2 & 1 & 1 & \\
\hline \multirow[t]{2}{*}{ Religion } & & 2 & 1 & 1 & \\
\hline & & & & & 20 \\
\hline \multicolumn{6}{|l|}{ Simon Fraser } \\
\hline English & 1 & 2 & 2 & 3 & \\
\hline History & & 1 & 1 & 1 & \\
\hline Philosophy & & 2 & 2 & 2 & \\
\hline Poetry criticism & & 2 & 3 & 3 & \\
\hline \multirow[t]{2}{*}{ Visual arts } & & 2 & 3 & 3 & \\
\hline & & & & & 33 \\
\hline \multicolumn{6}{|l|}{ Guelph } \\
\hline Art history & 2 & 2 & 1 & 1 & \\
\hline Canadian literature & & 2 & 2 & 2 & \\
\hline English literature & & 1 & 2 & 2 & \\
\hline Philosophy & & 2 & 2 & 2 & \\
\hline \multirow[t]{2}{*}{ Religion } & & 2 & 2 & 2 & \\
\hline & & & & & 29 \\
\hline Average Score for the $\mathrm{C}$ & hensive cate & & & & 27.3 \\
\hline
\end{tabular}


TABLE 3

Ratings of Pathfinders of Universities in the Undergraduate Category (where 3 is the highest score possible)

\begin{tabular}{|c|c|c|c|c|c|}
\hline University & Consistency & Scope & Readability & Use & Total \\
\hline \multicolumn{6}{|l|}{ Trent } \\
\hline Classical studies & 3 & 1 & 1 & 1 & \\
\hline English & & 1 & 1 & 1 & \\
\hline History & & 1 & 1 & 1 & \\
\hline Modern languages & & 1 & 1 & 1 & \\
\hline \multirow[t]{2}{*}{ Philosophy } & & 1 & 1 & 1 & \\
\hline & & & & & 18 \\
\hline \multicolumn{6}{|l|}{ St. Francis Xavier } \\
\hline Art & 2 & - & - & - & \\
\hline English & & 1 & 2 & 2 & \\
\hline History & & 1 & 2 & 2 & \\
\hline Music & & - & - & - & \\
\hline \multirow[t]{2}{*}{ Philosophy } & & 1 & 2 & 2 & \\
\hline & & & & & 17 \\
\hline \multicolumn{6}{|l|}{ Acadia } \\
\hline Church history & 2 & 1 & 1 & 1 & \\
\hline Classics & & 1 & 1 & 1 & \\
\hline English & & 2 & 1 & 1 & \\
\hline History & & 1 & 2 & 1 & \\
\hline \multirow[t]{2}{*}{ Systematic theology } & & 1 & 1 & 1 & \\
\hline & & & & & 19 \\
\hline Average Score for the Un & graduate Categ & & & & 18 \\
\hline
\end{tabular}

sonably comprehensive without being excessively complex. The only library to consistently include both a definition of the subject referred to and a note on the pathfinder's purpose is Guelph. Simon Fraser does so for select subjects. Many of the pathfinders are also extremely broad. Acadia and UBC, for example, have each produced one pathfinder to cover all of history and another to cover the complete area of English literature. Such pathfinders are, perhaps, too broad to be very helpful. For example, Acadia's history pathfinder addresses the history of countries around the world, from all the ages. One section that gets lost in the vastness is the "Middle Ages and Reformation," which lists only three print sources, none of them geographically specific. Such a resource would have limited value for students who are almost always expected to write on quite specific and manageable topics within a certain historical time or place.
This problem is common to all the pathfinders analyzed, although Trent and Queen's have posted separate ones for the history of different geographical areas. Also, Simon Fraser and Guelph have created a variety of English literature pathfinders, making separate ones for poetry and Canadian literature, for example. The pathfinders from all schools incorporate several types of resources, including reference books, indexes, and Internet resources, in many cases. However, Simon Fraser and Queen's alone include a guide to using the library catalog within the pathfinder. Guelph, St. Francis Xavier, McGill, and Acadia mention the catalog as an important resource and provide a link to it but do not include searching tips in the pathfinder. Further, although the Web sites of Trent, Waterloo, and UBC provide instruction on using the library's catalog, no mention of the catalog itself is made within their subject pathfinders. 


\section{Readability}

The importance of creating pathfinders that are readable to the students they are intended for cannot be overemphasized. The more explanatory material that is included, the more likely it is that jargon such as "bibliographic monographs" will appear. However, without a description of what particular sources contain or are useful for, the pathfinder loses some of its value. The best pathfinders in terms of readability are Simon Fraser's, which include descriptive and evaluative annotations for the listed resources. Some pathfinders of Queen's and UBC also contain annotations. Waterloo's pathfinders contain some very brief descriptions, as does Acadia's guide for history. The others primarily list book titles and other resources with little additional information, although Guelph does include a good explanation of the role of indexes and abstracts elsewhere on the Web site. On the whole, the pathfinders were free of unexplained jargon, but Trent's pathfinders all include a section entitled "Monographic Bibliographies," for which no definition is provided.

Also contributing to readability is the level of clarity achieved through section headings and internal links. Because most electronic pathfinders are not as straightforward to find and read as printed copies are, it is critical that they be clear and not misleading. Two libraries did not completely meet this challenge. The statement of the purpose of the pathfinders at Simon Fraser declares that they provide "an entry into the resources of the World Wide Web." However, all except the history pathfinder include lists of print sources specific to Simon Fraser as well. Clearly, the description does not match the product. Waterloo and McGill post a general statement that their pathfinders contain both online and print sources, but Waterloo's English pathfinder lists electronic resources exclusively. This lack of clarity is complicated further by headings that do not actually describe that to which they are linked. For example, long and detailed lists of resources in Waterloo's libraries are found under the link "Quick Facts and Bibliographies." Again, the description does not easily lead a user to this resource. Another issue relating to readability is the state of the links included in electronic pathfinders. Although they are admittedly difficult to maintain, some effort must be made to check them regularly. The pathfinders for every library contained some dead links, but the only significant problems related to this were those instances in which the links to specific pathfinders did not work, which was the case at St. Francis Xavier's Web site. Neither the art nor the music headings linked to anything at all, meaning that if there were actually pathfinders there, they were inaccessible.

\section{Use}

Long lists of books, indexes, and Web sites alone do not teach students how to conduct research. But pathfinders that include instructions on the library catalog, LOC subject headings, the purpose of journal indexes and abstracts, and links to Web sites that serve as gateways to a variety of information on their topic help users learn how to search. This is an especially important component of pathfinders with a very broad subject range, such as history. If the section on medieval history lists only two sources, students may be able to find more on their own if they are introduced to different ways of searching. Trent's pathfinders simply list books and call numbers and contain no explanatory material whatsoever. St. Francis Xavier's pathfinders list call number areas to browse and make brief mention of the library catalog but give no details about using it. The pathfinders created at Acadia alert students to a full range of resources but do not list any LOC subject headings or provide instruction on how to use the library catalog or how the indexes work. Those of Waterloo also mention several types of resources, excluding the library catalog, but do not include explanatory material. Guelph goes one step further by including a section on subject headings as well as a list of call number ranges to browse. However, this section is 
separate from the actual list of information sources, so it can be missed easily. In contrast to the others, Simon Fraser's pathfinders are explicitly intended to be teaching tools, as are most of those posted by Queen's. Every type of resource is explained, and details on how to use the library catalog (including the difference between subject and keyword searches) and journal indexes are incorporated into the pathfinder.

Another factor contributing to readability is the structure of the pathfinder. For example, although Acadia's classics, English, and history pathfinders are divided into sections based on either time periods or geographical location, those for church history and systematic theology are listed only alphabetically. Because they are not divided along chronological or denominational lines, they separate, for example, the Encyclopedia Judaica from the Jewish Encyclopedia. In Trent's and McGill's pathfinders, the Internet resources are listed apart from the main subject guides so that one would have to look under history in two places to find both types of resources. Clearly, the more detailed a pathfinder is, the more complex its structure tends to become. This can (but does not necessarily have to) lead to two problems in particular. First, it is difficult to know what heading to look under when you do not know how the resource you seek has been categorized, and, second, if you do not know what you are looking for, where should you start? The presence of too many headings may be confusing, and users may not take the time to explore all the options to find what they want.

\section{Discussion and Recommendations}

It is a matter of fact that any prescriptive guidelines will not necessarily be followed and the format and quality of pathfinders will continue to vary. For example, whereas some librarians provide long lists of resources, others prefer to list a carefully chosen selection. In addition, some librarians work in isolation from others who create pathfinders, often sac- rificing consistency in both format and content. Such problems arise when creating both electronic and print pathfinders, but electronic pathfinders raise additional issues. Printed pathfinders tend to be simple and straightforward in structure. There is a tendency to abandon this simplicity in electronic pathfinders, largely because it is easy to provide links to so many other Web pages, where explanations about the library catalog and journal indexes are provided. Interestingly, those that were rated high in the consistency category are the shortest and simplest (although not the best) pathfinders. One could follow these and other links almost endlessly, it seems, which make the pathfinders sprawling rather than compact. Simply put, very few of the electronic pathfinders studied can be viewed in their totality from a single location. This complexity of structure, though admirable in the depth of coverage it can facilitate, moves pathfinders away from their role of being a nonconfusing introduction to research and resources. Although it is not being advocated that electronic pathfinders contain references to fewer types of resources, it is suggested that they be listed together somewhere, as is the case in printed ones. In addition to the clarity that would be gained, which is especially important for beginning researchers such as undergraduates, it would make electronic pathfinders easier to print.

Lists of books, call numbers, and instructions from electronic pathfinders will likely be printed out by those who intend to use them because it is easier for many people to refer to information that is in print and portable. Although some pathfinders are set up in a way that makes it simple to be printed in their entirety, others that contain several different sections on different Web pages are not so easy to print. Ease of printing, therefore, should be a consideration when creating electronic pathfinders. Further, if the Web addresses for links are not given, it is difficult for them to be accessed from anywhere but inside the pathfinder itself. 
Doing so may not always be convenient, particularly if a user sees the item listed but wishes to access it at another time. A final point to make about electronic pathfinders, in particular, pertains to accessibility. Although they may be more accessible online than print pathfinders found only in a library, this will only be the case if they are easily found on the library's Web site. Headings such as "Find Library Resources by Subject" are direct and obvious. However, following a path from "Services" on the home page to "Reference" and then "Subject Guides" leaves open the possibility that such resources may remain hidden from those who are not told about them directly. Because so much work is put into producing helpful and readily usable pathfinders, libraries should be careful not to hide them deep within their Web sites.

\section{Conclusion}

The increasingly common practice of making pathfinders available electronically has raised the need to assess current guidelines for creating pathfinders in general, and to identify special considerations when making electronic pathfinders in particular. Through an analysis of fortyfive pathfinders created at nine Canadian universities, it has been concluded that existing recommendations regarding the consistency, scope, readability, and usability of pathfinders are not uniformly followed by the creators of electronic pathfinders. Further, no guidelines pertaining to specifically electronic pathfinders have been set out, even though their unique format renders existing guidelines inadequate. Because problems clearly exist, guidelines have to be modified to address them.

Further research on the use that students actually make of pathfinders would be helpful in testing the suggestions made here, as well as in formulating comprehensive guidelines for the construction of specifically electronic pathfinders. Also, determining students' preferred format of pathfinder-paper or electronic-would help librarians tailor their services to the needs of users. The results of such research, along with the observations made here, would provide librarians with the background knowledge necessary to make the most effective pathfinders for students.

\section{Notes}

1. This article is the result of research conducted during a reading class in the summer of 2000 at the Faculty of Information Studies, University of Toronto. The class was supervised by Juris Dilevko, and I would like to thank him for his guidance.

2. Charles H. Stevens, M. P. Canfield, and J. J. Gardner, "Library Pathfinders: A New Possibility for Cooperative Reference Service," College \& Research Libraries 34 (Jan. 1973): 41.

3. Alice Sizer-Warner, "Pathfinders: A Way to Boost Your Information Handouts beyond Booklists and Bibliographies," American Libraries 14 (Mar. 1983): 151.

4. Patricia Breivik, Planning the Library Instruction Program (Chicago: ALA, 1982), 76.

5. Lorna Peterson and Jamie W. Coniglio, "Readability of Selected Academic Library Guides," $R Q 27$ (winter 1987): 233-39.

6. Harry Nuttall and Sonja McAbee, "Pathfinders On-line: Adding Pathfinders to a NOTIS On-line System," College \& Undergraduate Libraries 4 (spring 1997): 77-79.

7. Corinne Laverty, "Library Instruction on the Web: Inventing Options and Opportunities," Internet Reference Services Quarterly 2 (summer/fall 1997): 66.

8. Jim M. Kapoun, "Re-thinking the Library Pathfinder," College \& Undergraduate Libraries 2 (spring 1995): 93.

9. Ibid., 96.

10. Ole R. Holsti, Content Analysis for the Social Sciences and Humanities (Reading, Mass.: Addison-Wesley, 1969). 